\title{
Ethics in Publishing: An Opinion on its Importance
}

\author{
Mohd. Kamran Khan', Anamika Pandey ${ }^{*}$, Saumya Choudhary², Kamer Gulcan', Sheeba \\ Khan $^{3}$, Shivani Rustagi ${ }^{4}$, George Thomas ${ }^{2}$, Mehmet Hamurcu${ }^{1}$, Sait Gezgin ${ }^{1}$ and Erdogan E. \\ Hakki $^{1 *}$ \\ ${ }^{1}$ Department of Soil Science and Plant Nutrition, University of Selcuk, Konya, 42079, Turkey \\ ${ }^{2}$ Department of Molecular and Cellular Engineering, JSBB, Sam Higginbottom Institute of Agriculture, \\ Technology and Sciences, Allahabad, India \\ ${ }^{3}$ Department of Food Science and Technology, WCFDT, Sam Higginbottom Institute of Agriculture, Technology \\ and Sciences, Allahabad, India \\ ${ }^{4}$ Amity Institute of Food Technology, Amity University, Noida, India
}

\section{ABSTRACT}

A research effort actually comes in to effect when it is published and becomes available to the scientific community; however, publishing it after following the required ethics is an equal challenge. Since last few years, a number of agencies specifically medical organizations and publishing editors have released several guidelines to resolve the issues regarding the conflicts related to publications and resolve the issues. In this communication we provide the required guidelines about publication ethics in a simple form so that they can be easily followed. This article may contribute towards spreading the awareness in the researchers regarding publication ethics may diminish the research misconduct.

\section{INTRODUCTION}

Assumption, interpretation and experimentation are the basic pillars of science. In the past, thousands of scientists worked in several fields without any social boundaries (Maqbool et al. 2014). Every person should have the authority to utilize scientific innovations for a favorable life style. A shared understanding between the government policies, scientists and industries is required for research upgrading. Innovative ideas should be largely shared among the scientific community to benefit the entire mankind. Publication is the best way for sharing ideas, innovations and views to the scientific world. It is last and most crucial phase of

\section{ARTICLE INFORMATION:}

*Corresponding Author: anamika@selcuk.edu.tr, eehakki@selcuk.edu.tr

Received $11^{\text {th }}$ Jan, 2018

Accepted after revision 21 $1^{\text {st }}$ March, 2018

BBRC Print ISSN: 0974-6455

Online ISSN: 2321-4007 CODEN: USA BBRCBA

Thomson Reuters ISI ESC / Clarivate Analytics USA and Crossref Indexed Journal

NAAS Journal Score 2017: 4.38 SJIF 2017: 4.196

- A Society of Science and Nature Publication, Bhopal India 2018. All rights reserved.

Online Contents Available at: http//www.bbrc.in/

DOI: $10.21786 / \mathrm{bbrc} / 11.1 / 1$ 
a successful research project. It is the outcome of long term efforts on careful preparations and experimental analysis (Derntl 2014). As most of the research projects are directly or indirectly supported through public investment, it should be developed for the benefits of entire society. A detailed description of the performed procedures should be universally accessible and easily acceptable. As a particular objective is responsible for raising so many scientific aims consequently affecting the entire world, publications should be comprehensive, truthful, correct, and fair and should not give deceptive information (Titus et al. 2008; Shaw and Erren 2015; Resnik and Shamoo 2017).

\section{ROOTS OF A RESEARCH PUBLICATION}

\section{Consistency in Methodology}

The researchers should follow all the ethical and legislative guidelines while accomplishing the research. Standard methodology should be employed for data investigation. Information provided in the publications should be liability of all the authors (Wager and Kleinert 2010). Researchers should systematically control and organize the research specifically for conclusions, statistical facts and data presentations (Wager and Kleinert 2013; Awais 2015).

\section{Truthfulness in Data}

Honesty is the best policy not only in life style but also in research. Data should not be fabricated or manipulated (Martinson et al. 2005). Related pictures should be presented in original form without any ambiguous modification (White 2007). All the efforts should be made to explain the methodology and results in a way so that it can be followed by other researchers. All the information including contradictory and strange outcomes against the expected results should be presented in their original form. It is responsibility of all the authors to convey with editor on finding any gaffe in submitted or published articles. All authors should help in corrections of manuscript whenever it is asked by editor or reviewers (Wager and Kleinert 2010; Wager and Kleinert 2013; Awais 2015).

All the previous relevant works should be included and cited accordingly. However, only those citations should be included that is related to the work and can guide the future researchers to get a complete scenario of the scientific problem (Ball 2002; Poulton 2007; Kamat and Schatz 2014; Damineni et al 2015).

\section{Innovativeness}

The work submitted to any journal should be innovative and not submitted at two platforms at a time. If co-sub- mitted or co-published, it should be brought in to notice of editors and reader (Uzun 2013). Several publications developed from the same project should be differentially presented with different information and benefits for the researchers. Copyright laws should be considered before publishing or reproducing any data. Statistical or other informative data included from previous publications should be precisely acknowledged. Authors should adhere to publisher guidelines and send the manuscript to one journal at a time. All the queries and publishing issues of editors' and reviewers' should be handled effectively (COPE 2009; Wager et al. 2009; Wager and Kleinert 2013; Awais 2015). Actual outcomes should be reflected in the entire work and should not include any unconfirmed results.

\section{Precision or Accuracy/ Clarity/ Unambiguity}

Authors should reveal all the equipments, funding resources and other aids employed in the research. Role of funding agencies or external supports in performing the research should be clearly mentioned in the publication (Masic et al. 2014). Authors should obey journal and institutional regulations and specify all the conflicts of interest (Dhammi and Haq 2017).

\section{Proper Authorship and Acknowledgement}

This is one of the most crucial and sensitive phases reflecting team work efforts in solving scientific problem. Authorship ascertains the liability and praise for the people who contribute to bring a scientific issue to a publication level (Marusic et al. 2006; Wager 2009; Wager and Kleinert 2013; Awais 2015).

Most of the guidelines emphasize that authorship should be given to a candidate only if he/she made a significant contribution in following:

- designing the research

- collecting and inferring the data

- drafting or critically revising the manuscript

People who perform the work and take the accountability for the research should get the credit and listed as authors.

Authorship, types and the number of publications should be discussed at the time of planning the research project (Claxton et al. $2005 \mathrm{a}$, b). At the time of writing a project proposal, decide on the things to be done, what will be done by whom and in what duration. A transparency and confirmation about each role should be maintained. Views of all the participants should be considered on the basis of their contribution in the work. A proof of these views and decisions should be kept. Every team must have a written conformity on authorship before the article is written. This is to diminish the disagree- 
ment at final stage, when all the efforts have been put by the deserved members. The acknowledgments can be utilized to pay gratitude towards those who indirectly added to the work like providing the experimental material or research facilities etc. Utmost care should be taken that a person deserves to hold an authorship should not be included in the acknowledgement section (Graf et al. 2007; Peh and Ng 2009; Tarkang et al. 2017).

Articles addressing broader audience and that are beneficial for major parts of the society are mostly preferred for publication. Manuscripts that are innovative, noteworthy, well-planned and well written are the main focus of all the reputed journals.

\section{CONCLUSION}

Generally, articles on publication ethics emphasize on the responsibilities of publishing agencies, editors, academic institutes and authors to diminish the possibilities of plagiarism and research misconduct. However, limited discussion has been made on the ethics in allocation of authorship in publication. As authorship assignment is the foundation that may strengthen the thought of publication ethics at every step, it should be prioritize in research and publication world. Although publication agencies confirm the contribution of authors, they are naturally unable to control the cases where authorships are not allocated to worthy candidates. Hence, scientific groups and team of authors need to be righteous, understandable and answerable on publication ethics. As concluding remarks, publication ethics should be deeply considered by different players involved in the scientific world specifically authors who make it available to the society.

\section{REFERENCES}

Awais PSM (2015) Responsible research publication: international standards for authors. Annals of King Edward Medical University 4: 280\%V 220.

Ball P. (2002). Paper trail reveals references go unread by citing authors. Nature. 420: 594

Claxton L.D. (2005a). Scientific authorship. Part 1. A window into scientific fraud? Mutation Research. 589:17-30.

Claxton LD. (2005b). Scientific authorship. Part 2. History, recurring issues, practices, and guidelines. Mutation Research. 589: 31-45.

Committee on Publication Ethics (COPE). (2009). COPE code of conduct. http:// publicationethics.org/code-conduct (accessed 24 Apr 2009).

Damineni R., Sardiwal K., Waghle S. and Dakshyani M. (2015) A comprehensive comparative analysis of articles retracted in 2012 and 2013 from the scholarly literature. Journal of
International Society of Preventive and Community Dentistry, 5(1):19-23.

Derntl M. (2014). Basics of research paper writing and publishing. International Journal Technology Enhanced Learning. 6(2): 105-123.

Dhammi I.K. and Ul Haq R. (2017) Ethics of medical research and publication. Indian Journal of Orthopaedics, 51(1):1-3.

Graf C., Wager E., Bowman A., Fiack S., Scott-Lichter D. and Robinson A. (2007). Best Practice Guidelines on Publication Ethics: A Publisher's Perspective. International Journal of Clinical Practice. 61 (Suppl. 152): 1-26.

Kamat P., and Schatz G.C. (2014) Cite with a Sight. The Journal of Physical Chemistry Letters, 5(7):1241-1242.

Maqbool F., Bahadar H. and Abdollahi M. (2014). Science for the benefits of all: The way from idea to product. Journal of Medical Hypotheses and Ideas. 8: 74-77.

Martinson B.C., Anderson M.S., de Vries R. (2005). Scientists behaving badly. Nature. 435: 737-738.

Marusic A., Bates T., Anic A. and Marusic M. (2006). Howthe structure of contribution disclosure statements affects validity of authorship: a randomized study in a general medical journal. Current Medical Research and Opinion. 22:1035-1044.

Masic I., Hodzic, A. and Mulic S. (2014). Ethics in Medical Research and Publication. International Journal of Preventive Medicine. 5(9): 1073-1082.

Peh W.C. and Ng K.H. (2009) Authorship and acknowledgements. Singapore medical journal, 50(6):563-565; quiz 566.

Poulton A. (2007): Mistakes and misconduct in the research literature: retractions just the tip of the iceberg. The Medical journal of Australia, 186(6):323-324.

Resnik D.B. and Shamoo A.E. (2017) Fostering Research Integrity. Accountability in Research, 24(6): 367-372.

Shaw D.M. and Erren T.C. (2015) Ten Simple Rules for Protecting Research Integrity. PLOS Computational Biology, 11(10):e1004388.

Tarkang E.E., Kweku M. and Zotor F.B. (2017) Publication Practices and Responsible Authorship: A Review Article. Journal of Public Health in Africa, 8(1):723.

Titus S.L., Wells J.A. and Rhoades L.J. (2008). Repairing research integrity. Nature. 453: 980-982.

Uzun C. (2013). Multiple Submission, Duplicate Submission and Duplicate Publication. Balkan Medical Journal. 30: 1-2.

Wager E. (2009). Recognition, reward and responsibility:Why the authorship of scientific papers matters. Maturitas 62: 109112.

Wager E. and Kleinert S. (2010). Responsible research publication: international standards for authors. A position statement developed at the 2nd World Conference on Research Integrity, Singapore, July 22-24, 2010. Chapter 50 in: Mayer T \& Steneck N (eds) Promoting Research Integrity in a Global Environment. Imperial College Press / World Scientific Publishing, Singapore (pp 309-16). (ISBN 978-981-4340-97-7) 
Wager E. and Kleinert S. (2013) Why do we need international standards on responsible research publication for authors and editors? Journal of Global Health, 3(2):020301.

Wager E., Fiack S., Graf C., Robinson A. and Rowlands I. (2009). Science journal editors' views on publication ethics: results of an international survey. Journal of Medical Ethics, 35: 348-353.

White C. (2007). Software makes it easier for journals to spot image manipulation. BMJ., 334, 607. 